\title{
PERUMUSAN STRATEGI BERSAING PADA GRAND MALABAR HOTEL
}

\author{
Ivan Godang Wardiman ${ }^{1}$ \\ Lukman Mohammad Baga ${ }^{2}$ \\ Popong Nurhayati $^{3}$ \\ ${ }^{1}$ Sekolah Bisnis, IPB University \\ Email: ivan62@apps.sb.ipb.ac.id \\ ${ }^{2}$ Departemen Agribisnis, Fakultas Ekonomi dan Manajemen IPB University \\ Email: 1ukmanba@apps.ipb.ac.id \\ ${ }^{3}$ Sekolah Bisnis, IPB University \\ Email: popongnurhayati14@gmail.com
}

\begin{abstract}
The industry 4.0 revolution era, the hotel competitive rivalry competition, and the covid-19 pandemic are challenges for every industry to compete, especially the hospitality industry. Faced with this situation, a strategy is needed in winning the competition. This study is aimed to formulate a competitive strategy at the Grand Malabar Hotel in the midst of fierce competition in Bandung hospitality industry. This study uses primary and secondary data collected through observation, questionnaires, interviews, literature studies and related journals. This study combaines quantitative and qualitative approaches at the same time to optain optimal results. Importance-Performance Analysis (IPA) and Blue Ocean Strategy (BOS) are used as the methods of this study. The result of this study shows that currently the Grand Malabar Hotel is entering into red ocean. There are 13 competitive factors analyzed, 3 of which must be eliminated, 1 factor must be subtracted, and 7 factors must be increased. The nnovation has been made by creating 6 factors, including: (1) cooperation with travel agents, (2) creating hotel website, (3) information on tourist attractions, (4) utilization of IoT, (5) self service check-in kiosks, (6) rooftop cafe. The strategy formulation has been tested and commercially feasible to be implemented by Grand Malabar Hotel.
\end{abstract}

Keywords: Blue ocean strategy (BOS), competitive strategy, hotel, importance-performance analysis (IPA), value innovation.

\section{PENDAHULUAN}

Revolusi industri 4.0 menjadi sebuah era yang memiliki pengaruh besar dalam model bisnis. Munculnya teknologi canggih seperti internet of thing (IoT), artificial intelligence, dan big data menjadi sebuah peluang baru bagi industri. Perubahan yang begitu cepat akibat perkembangan teknologi ini juga dikenal dengan fenomena disruptive innovation (Schwab, 2016). Hal inilah yang mengharuskan setiap industri untuk bertansformasi ke arah digital agar mampu bersaing di masa depan.

Menghadapi hal di atas, dibutuhkan suatu pemikiran strategis atau strategic thinking. Strategic thinking merupakan suatu cara untuk melihat peluang yang ada dan memanfaatkan peluang tersebut untuk meningkatkan kinerja bisnis, sehingga tujuan jangka panjang perusahaan dapat tercapai (David, 2011; Uchenna \& Ekwy, 2019)

Kota Bandung merupakan kota wisata yang banyak dikunjungi oleh wisatawan baik wisatawan lokal maupun mancanegara. Menurut penelitian Widyastutik et al. (2020), sektor jasa pariwisata Indonesia merupakan sektor yang memiliki tren yang terus meningkat, salah satunya adalah hotel. Hotel mengalami peningkatan yang cukup signifikan selama 5 tahun terakhir. Data peningkatan hotel ditampilkan pada Tabel 1. 
Tabel 1. Jumlah hotel berbintang di Kota Bandung tahun 2015-2019

\begin{tabular}{ccc}
\hline Tahun & Jumlah hotel (unit) & Pertumbuhan (\%) \\
\hline 2015 & 124 & - \\
2016 & 147 & 18,55 \\
2017 & 162 & 10,20 \\
2018 & 180 & 11,11 \\
2019 & 195 & 8,33 \\
\hline
\end{tabular}

Sumber: Badan Pusat Statistik (2020)

Tabel 1 menunjukkan bahwa imbas dari peningkatan jumlah hotel berbintang di Kota Bandung akan menyebabkan terjadinya persaingan antar hotel yang semakin ketat. Hotel berbintang di Kota Bandung salah satunya adalah Grand Malabar Hotel. Hotel ini masuk ke dalam kategori hotel bintang tiga.

Berdasarkan rating dari Traveloka, Grand Malabar Hotel mendapatkan rating 7,8. Ini masih di bawah kompetitor lainnya seperti hotel Ibis Budget Asia Afrika, Chara Hotel, dPalma Hotel, dan Collection O 25 Hotel Baltika yang masing-masing mendapat rating 8,3;8,2; 8,2; 8,0 (Traveloka, 2020). Grand Malabar Hotel saat ini hanya memasarkan jasanya melalui Online Travel Agent (OTA), tidak memiliki website dan tidak aktif di media sosial. Hal ini tentu tidak akan memberikan hasil yang optimal bagi Grand Malabar Hotel. Tahun 2020 menjadi tahun yang sulit khususnya bagi industri hotel, termasuk Grand Malabar Hotel, karena mengalami dampak yang besar. Penelitian lain menyebutkan bahwa pandemi Covid-19 memberikan dampak parah bagi hotel karena wisatawan dilarang masuk ke Indonesia. Dampak ini juga dirasakan oleh industri logistik, kesehatan, perdagangan, dan rumah tangga (Sugihamretha, 2020; Susilawati et al., 2020).

Dalam menghadapi persaingan yang ketat, rating yang masih di bawah pesaing, strategi saat ini yang belum optimal, ditambah kondisi pandemi Covid-19, Grand Malabar Hotel perlu merumuskan strategi baru agar tetap dapat bertahan dan bersaing di masa depan. Adicandra (2017); Kusnita (2019); Thursena (2016) telah melakukan penelitian pada industri hotel di Indonesia, tetapi belum ada yang menghasilkan strategi bersaing yang mempertimbangkan nilai kepentingan dari konsumen hotel tersebut. Penelitian ini bertujuan untuk: (1) mengidentifikasi faktor-faktor kompetisi industri hotel di Kota Bandung; (2) mengetahui posisi persaingan Grand Malabar Hotel saat ini; (3) merumuskan strategi bersaing yang layak secara komersil bagi Grand Malabar Hotel.

\section{KAJIAN PUSTAKA}

Blue ocean strategy merupakan suatu pasar yang belum terjelajahi, sehingga harus menciptakan permintaan untuk pertama kalinya (Kim \& Mauborgne, 2005). Menurut Leavy (2018) blue ocean strategy adalah proses inovasi nilai yang menciptakan permintaan baru dengan melakukan penawaran baru.

Beberapa peneliti seperti Kosasih \& Indriyani (2014) menyebutkan bahwa dengan menerapkan blue ocean strategy suatu perusahaan dapat menciptakan pasar baru. Shyam \& Geevarathna (2019) membuktikan dalam penelitiannya bahwa suatu perusahaan apabila fokus terhadap variabel ciptakan, tingkatkan, kurangi, dan hilangkan, akan bertahan dalam jangka Panjang. Arifin \& Abdillah (2018) menyebutkan bahwa blue ocean strategy membantu industri-industri kecil untuk mencari inovasi-inovasi terbaru agar dapat bersaing. Kemudian Kusnita (2019) mengemukakan bahwa untuk mencapai inovasi nilai ada beberapa yang harus dilakukan pada hotel seperti meningkatkan kualitas sumberdaya manusia, menjaga kualitas website dan penggunaan public figure. Dari beberapa penelitian tersebut didapatkan bahwa penggunaan blue ocean strategy dinilai efektif dalam persaingan bisnis saat ini dan membawa dampak positif terhadap suatu bisnis.

\section{METODE PENELITIAN}

Penelitian ini dilakukan pada bulan Oktober hingga bulan November 2020. Penelitian berlokasi di Grand Malabar Hotel yang beralamat di Jl. Malabar No. 2, Keluruhan Malabar, Kecamatan Lengkong, Kota 
Bandung. Data yang digunakan adalah data primer yang didapat dari observasi, kuesioner, dan wawancara, sedangkan data sekunder didapat dari hasil internet, studi literatur, dan jurnal-jurnal terkait.

Metode penelitian menggunakan pendekatan kuantitatif dan kualitatif. Pendekatan kuantitatif digunakan untuk mengolah data hasil kuesioner yang didapat dari responden mengenai faktor-faktor kompetisi pada industri hotel. Pendekatan kualitatif digunakan untuk merumusakan strategi.

Sampel pada penelitian ini dibagi ke dalam dua tahapan. Kuesioner tahap pertama dibagikan ke 60 orang responden yang terdiri dari 30 orang responden Grand Malabar Hotel dan 30 orang responden Collection O 25 Hotel Baltika. Tahapan kedua, kuesioner dibagikan kepada 15 orang responden yang berasal dari Grand Malabar Hotel saja. Syarat responden adalah orang yang pernah menginap minimal satu kali pada hotel tersebut. Metode pengambilan sampel pada penelitian ini adalah metode purposive sampling. Metode ini digunakan untuk menilai kinerja dan kepentingan faktor-faktor kompetisi industri hotel di Kota Bandung. Setelah didapatkan data tersebut, dilanjutkan perumusan strategi melalui wawancara dengan pihak internal yaitu manajer Grand Malabar hotel yang berjumlah 1 orang. Total sampel untuk pengambilan data dari konsumen hotel dan internal hotel berjumlah 76 orang. Untuk variabel dan definsi operasional yang digunakan akan dijelaskan pada Tabel 2 berikut.

Tabel 2. Variabel dan definisi operasional

\begin{tabular}{|c|c|c|c|}
\hline No & Variabel & Definisi & Indikator \\
\hline 1 & Product & $\begin{array}{l}\text { Produk merupakan segala sesuatu } \\
\text { yang ditawarkan kepada pasar untuk } \\
\text { memuaskan suatu keinginan atau } \\
\text { kebutuhan konsumen. }\end{array}$ & \begin{tabular}{ll}
1 & Kamar yang bersih \\
2 & Fasilitas kamar \\
3 & Fasilitas hotel \\
4 & Sarapan yang enak* \\
\multicolumn{2}{l}{ Sumber: Nadhifa \& Sharif (2019) }
\end{tabular} \\
\hline 2 & Price & $\begin{array}{l}\text { Harga adalah sejumlah uang yang } \\
\text { dikeluarkan untuk memperoleh suatu } \\
\text { barang atau jasa. }\end{array}$ & $\begin{array}{l}1 \quad \begin{array}{l}\text { Harga yang ditawarkan sesuai } \\
\text { dengan fasilitas }\end{array} \\
\text { Sumber: Caesari et al. (2015) }\end{array}$ \\
\hline 3 & Place & $\begin{array}{l}\text { Tempat merupakan suatu lokasi yang } \\
\text { ditentukan oleh perusahaan untuk } \\
\text { membuat produk atau jasa yang } \\
\text { ditawarkan mudah diperoleh dan } \\
\text { tersedia bagi konsumen yang dituju. }\end{array}$ & $\begin{array}{l}1 \quad \text { Lokasi strategis } \\
2 \quad \text { Parkir memadai } \\
\text { Sumber: Pristanto et al. (2012) }\end{array}$ \\
\hline 4 & Promotion & $\begin{array}{l}\text { Promosi adalah kegiatan untuk } \\
\text { mengkomunikasikan dan } \\
\text { memperkenalkan barang atau jasa dari } \\
\text { suatu perusahaan kepada target pasar. }\end{array}$ & $\begin{array}{l}1 \quad \text { Media online } \\
\text { Sumber: Pristanto et al. (2012) }\end{array}$ \\
\hline 5 & People & $\begin{array}{l}\text { Suatu kegiatan yang dilakukan oleh } \\
\text { karyawan perusahaan untuk memenuhi } \\
\text { kepauasan konsumen. }\end{array}$ & $\begin{array}{ll}1 & \text { Karyawan yang ramah } \\
2 & \text { Karyawan yang cepat memenuhi } \\
\text { kebutuhan konsumen. }\end{array}$ \\
\hline 6 & Proccess & $\begin{array}{l}\text { Proses merupakan suatu kegiatan yang } \\
\text { dilakukan untuk memasarkan jasa } \\
\text { kepada calon konsumen. }\end{array}$ & $\begin{array}{l}1 \quad \text { Menawarkan online reservation } \\
2 \text { Menawarkan fast check-out* } \\
\text { Sumber: Pristanto et al. (2012) }\end{array}$ \\
\hline 7 & $\begin{array}{l}\text { Physical } \\
\text { Evidence }\end{array}$ & $\begin{array}{l}\text { Bukti yang dimiliki oleh penyedia jasa } \\
\text { yang diberikan kepada konsumen } \\
\text { sebagai nilai tambah. }\end{array}$ & 1 Desain bangunan menarik* \\
\hline
\end{tabular}

* Faktor yang ditambahkan oleh peneliti 
Kuesioner pada penelitian ini terdiri dari 13 pertanyaan yang didapat dari beberapa summber seperti yang tercantum pada Tabel 2 di atas. Kemudian sebelum disebarkan ke responden kuesioner ini diuji menggunakan uji validitas dan realibilitas. Hasil uji validitas dan reliabilitas di tunjukkan pada Tabel 3.

Tabel 3. Hasil uji validitas

\begin{tabular}{llllc}
\hline Variabel & Indikator & r-hitung & r-tabel & Keterangan \\
\hline \multirow{3}{*}{ Product } & P1 & 0,440 & 0,361 & Valid \\
& P2 & 0,576 & 0,361 & Valid \\
Price & P3 & 0,388 & 0,361 & Valid \\
Place & P4 & 0,498 & 0,361 & Valid \\
Promotion & P5 & 0,396 & 0,361 & Valid \\
& P6 & 0,432 & 0,361 & Valid \\
People & P7 & 0,536 & 0,361 & Valid \\
& P8 & 0,374 & 0,361 & Valid \\
Physical evidence & P9 & 0,438 & 0,361 & Valid \\
\hline S10 & P13 & 0,636 & 0,361 & Valid \\
\hline
\end{tabular}

Sumber: Data diolah (2020)

Suatu item atau pertanyaan dinyatakan valid apabila nilai $r$-hitung $>$ r-tabel. Pada penelitian ini responden dalam uji validitas berjumlah 30 orang dan didapat nilai r-tabel yaitu 0.361 , sehingga berdasarkan Tabel 3 di atas bahwa semua item atau indikator dinyatakan valid. Berikut hasil uji reliabel pada Tabel 4 .

Tabel 4. Hasil uji reliabilitas

\begin{tabular}{llcc}
\hline Variabel & Indikator & Cronbach's Alpha & Keterangan \\
\hline \multirow{4}{*}{ Product } & P1 & 0,800 & Reliabel \\
& P2 & 0,789 & Reliabel \\
Price & P3 & 0,804 & Reliabel \\
Place & P4 & 0,796 & Reliabel \\
Promotion & P5 & 0,804 & Reliabel \\
& P6 & 0,803 & Reliabel \\
People & P7 & 0,795 & Reliabel \\
& P8 & 0,803 & Reliabel \\
Physical evidence & P9 & 0,799 & Reliabel \\
S10 & P11 & 0,784 & Reliabel \\
P12 & P13 & 0,795 & Reliabel \\
& & 0,796 & Reliabel \\
\end{tabular}

Sumber: Data diolah (2020)

Nilai Cronbach Alpha $(\alpha)$ merupakan suatu indikator untuk menentukan suatu item reliabel atau tidak. Apabila nilai Cronbach Alpha $(\alpha)>0,60$ maka dapat dikatakan reliabel. Berdasarkan Tabel 4 semua item dinyatakan reliabel.

Selanjutnya, Teknik analisis data menggunakan kanvas strategi, prinsip-prinsip blue ocean strategy, kerangka kerja empat langkah, serta skema ERRC-Grid yang dikombinasikan dengan metode IPA. Penelitian 
ini dimulai dengan identifikasi masalah yang terjadi pada Grand Malabar Hotel, lalu memelajari teori dan penelitian terdahulu tentang strategi yang cocok digunakan. Dalam penelitian ini menemukan 10 faktor kompetisi dan selanjutnya peneliti menambah 3 faktor untuk dianalisis, sehingga ada 13 faktor yang ada pada penelitian ini. Selanjutnya menggambarkan kanvas strategi masa kini untuk melihat posisi persaingan antara Grand Malabar Hotel dengan hotel pesaingnya. Kemudian merumuskan strategi menggunakan blue ocean strategy (BOS) dan importance-performance analysis (IPA), lalu munculnya kanvas strategi baru bagi Grand Malabar Hotel dan terkahir implikasi manajerial bagi hotel.

\section{HASIL DAN PEMBAHASAN}

Penelitian ini melibatkan sebanyak 75 orang responden. 60 orang responden mengisi kuesioner tahap pertama, dan 15 orang responden mengisi kuesioner tahap kedua. Pada tahap pertama ini 30 orang responden yang merupakan tamu dari Grand Malabar Hotel dan 30 orang responden merupakan tamu dari Collection O 25 Hotel Baltika.

Responden Grand Malabar Hotel dibagi menjadi beberapa aspek, yaitu: usia, alamat, jenis kelamin, jenis pekerjaan, tingkat pendapatan, tingkat pendidikan, jumlah kali menginap, durasi, jenis kamar saat menginap dan tujuan menginap. Dari 30 orang responden sebanyak 56,67\% adalah laki-laki dan paling banyak berusia 17-25 tahun (43,33\%). Responden mayoritas beralamat di Jawa Barat (56,67\%) dan memiliki pekerjaan sebagai pegawai swasta $(43,33 \%)$. Pendidikan terakhir responden mayoritas sarjana (S1), pendapatan yang paling banyak adalah 4-5 juta.

Responden Collection O 25 Hotel Baltika dibagi juga ke dalam beberapa aspek sesuai dengan responden Grand Malabar Hotel. Hasilnya dari 30 responden sebanyak 18 orang berusia 26-35 tahun dan $60,00 \%$ berjenis kelamin perempuan. Responden mayoritas juga di Jawa Barat $(56,67 \%)$ dan bekerja sebagai pegawai swasta sebanyak 50,00\%. Dari 30 orang responden sebanyak $60,00 \%$ memiliki Pendidikan terakhir sarjana (S1) dan sebanyak 40,00\% memiliki pendapatan di atas 5 juta.

\section{Faktor-Faktor Kompetisi Industri Hotel di Kota Bandung}

Proses penentuan faktor-faktor yang dimasukkan untuk dianalisis berjumlah 13 faktor. Ketiga belas faktor tersebut antara lain: kebersihan kamar, fasilitas kamar, fasilitas hotel, sarapan, harga yang ditawarkan, lokasi strategis, parkir memadai, memiliki media online, karyawan yang ramah, karyawan yang cepat tanggap, menawarkan online reservation, menawarkan fast check-out, dan desain bangunan.

\section{Kanvas Strategi Tahun 2020}

Kanvas strategi awal digunakan untuk melihat posisi persaingan Grand Malabar Hotel dan pesaingnya. Penilaian kinerja terhadap 13 faktor kompetisi antara Grand Malabar Hotel dan Collection O 25 Hotel Baltika terlihat pada Gambar 1. 


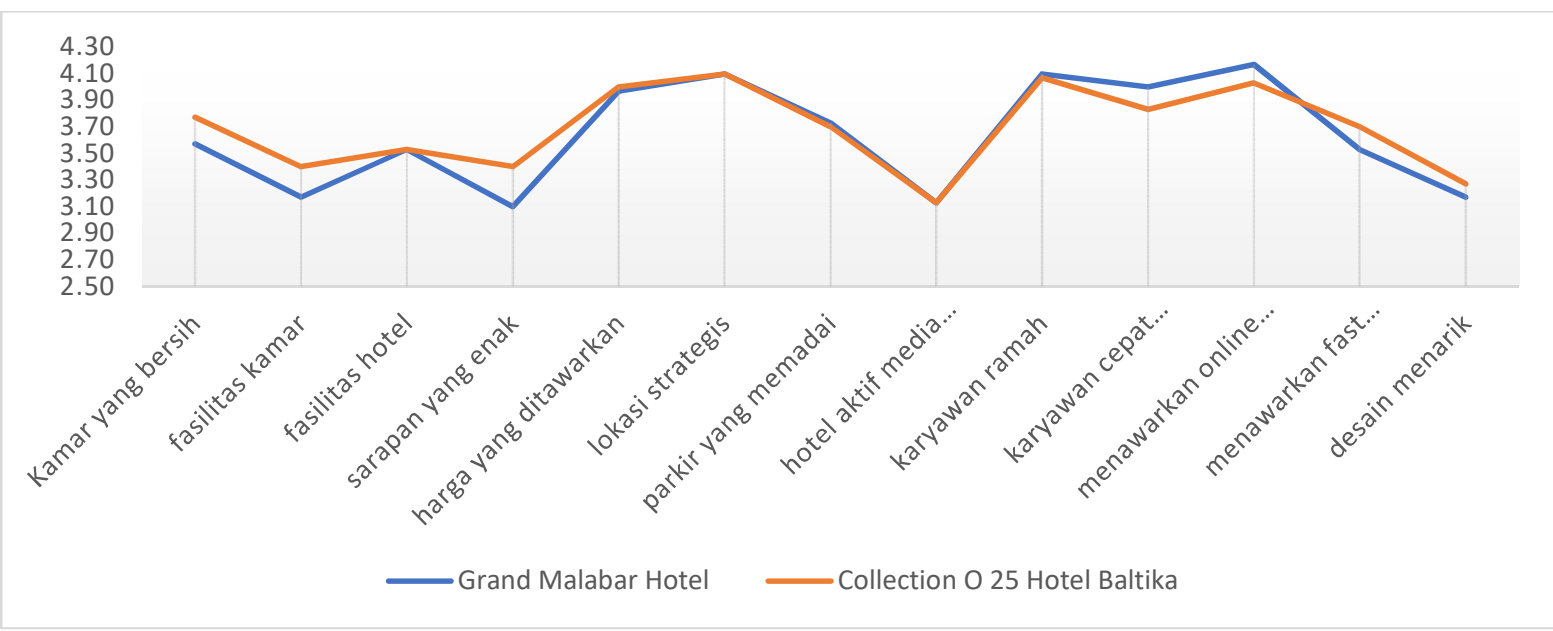

Sumber: Data diolah (2020)

Gambar 1. Kanvas strategi Grand Malabar Hotel tahun 2020

Gambar 1 menjelaskan bahwa posisi persaingan antara Grand Malabar Hotel dengan Collection O 25 Hotel Baltika itu sengit. Hampir setiap faktor pada kanvas strategi tersebut berdempetan. Hal inilah yang disebut samudera merah. Samudera merah merupakan situasi atau kondisi bahwa di industri itu bersaing secara gontok-gontokan (Kim \& Mauborgne, 2005).

\section{Perumusan Blue Ocean Strategy pada Grand Malabar Hotel}

\section{Prinsip 1: Mencari Peluang-peluang Strategis}

Prinsip pertama adalah sebuah tantangan bagi perusahaan untuk mencari peluang-peluang yang menguntungkan. Terdapat enam jalan untuk mencapai blue ocean yang harus dilakukan dengan benar.

\section{Mencermati industri-industri alternatif}

Dalam penelitian ini, industri alternatif dari sebuah hotel itu sebenarnya cukup banyak di zaman sekarang. Peneliti menyimpulkan alternatif dari hotel antara lain: villa, kos harian, apartemen, cottage, maupun homestay lainnya. Industri-industri ini memiliki bentuk dan tujuan yang berbeda, tetapi memiliki fungsi yang sama yaitu untuk memberikan jasa penginapan bagi yang ingin berwisata.

\section{Mencermati kelompok-kelompok strategis}

Grand Malabar Hotel sebagai industri hotel perlu mencermati kelompok-kelompok strategis yang ada. Grand Malabar Hotel yang merupakan hotel bintang 3 harus mencermati hotel bintang 4 atau 5 dalam hal pelayanan dan fasilitas yang diberikan. Selain itu, kelompok strategis lainnya seperti Reddors, Bobobox, atau Capsule Hotel yang merupakan pemain baru dengan menawarkan harga yang sangat terjangkau. Kelompok-kelompok ini yang harus dicermati bagi Grand Malabar Hotel, agar nantinya bisa menciptakan hotel yang menawarkan pelayanan dan fasilitas yang baik dengan harga yang terjangkau.

\section{Mencermati rantai pembeli}

Rantai pembeli dari industri hotel sebenarnya tidak hanya konsumen yang selalu menginap di hotel. Ada beberapa kelompok yang secara tidak langsung memengaruhi keputusan pembelian konsumen. Pada penelitian ini, rantai pembeli Grand Malabar Hotel setelah dianalisis seperti perusahaan swasta, lembaga pemerintahan, dan influencer. Influencer dapat memengaruhi keputusan pembelian seseorang dengan pendapat mereka terhadap hotel tersebut. Kemudian perusahaan swasta dan lembaga pemerintahan juga dapat menjadi konsumen potensial yang memanfaatkan kamar dan room meeting di Grand Malabar Hotel.

Mencermati penawaran produk dan jasa pelengkap 
Berdasarkan hasil analisis, memberikan kepuasan pelayanan terhadap konsumen atau tamu yang menginap merupakan hal yang bagus untuk meningkatkan citra hotel. Grand Malabar Hotel bisa menambahkan jasa pelengkap seperti informasi tempat wisata, transportasi antarjemput ke tempat wisata, sosial media, dan website hotel, sehingga ini membuka peluang bagi Grand Malabar Hotel untuk menaikkan penjualannya.

\section{Mencermati daya tarik emosional-fungsional pembeli}

Grand Malabar Hotel harus menerapkan daya tarik emosional dan fungsional bagi pembeli. Daya tarik emosional yang bisa diterapkan seperti suasana yang nyaman, menawarkan view Kota Bandung di malam hari, pembuatan taman di rooftop, memberikan breakfast yang unik dan menarik, kemudian di era Covid-19 tentu harus menerapkan protokol kesehatan seperti menyediakan handsanitizer, jaga jarak, dan penggunaan masker bagi seluruh pihak.

Daya tarik fungsional dapat diciptakan dengan menerapkan revolusi industri seperti penggunaan Internet of Thing (IoT), menawarkan WiFi yang stabil dan kencang. Menurut Suwarni et al. (2020), kunci agar industri bisa bertahan di zaman sekarang adalah dapat menawarkan akses yang cepat dan mudah bagi konsumen.

\section{Mencermati waktu}

Mencermati waktu berhubungan dengan menciptakan tren. Grand Malabar Hotel harus mampu menawarkan sesuatu yang lebih dibanding pesaingnya, seperti menawarkan apa yang ditawarkan hotel bintang 4 atau 5, lalu menawarkan kamar yang pas dan nyaman dengan fasilitas yang modern, menawarkan pelayanan yang baru seperti penggunaan robot maupun chatbot untuk melayani konsumen. Rangkuman kerangka kerja enam jalan terlihat pada Tabel 2.

\section{Tabel 2. Rangkuman kerangka kerja enam jalan}

\begin{tabular}{|c|c|}
\hline Kerangka kerja enam jalan & Keterangan \\
\hline Mencermati industri-industri alternatif & Homestay, apartemen, villa, kos harian, cottage \\
\hline \multirow[t]{2}{*}{ Mencermati kelompok strategis } & Menawarkan produk dengan mengombinasikan \\
\hline & $\begin{array}{l}\text { kelengkapan. fasilitas, pelayanan yang baik, dan harga } \\
\text { yang terjangkau }\end{array}$ \\
\hline Mencermati rantai pembeli & $\begin{array}{l}\text { Lembaga pemerintahan, perusahaan swasta, dan } \\
\text { influencer }\end{array}$ \\
\hline $\begin{array}{l}\text { Mencermati penawaran produk dan jasa } \\
\text { pelengkap }\end{array}$ & $\begin{array}{l}\text { Membuat informasi tempat wisata, transportasi PP } \\
\text { tempat wisata, sosial media, dan website hotel }\end{array}$ \\
\hline Mencermati daya tarik emosional- & Memanfaatkan teknologi modern, meningkatkan \\
\hline fungsional pembeli & $\begin{array}{l}\text { kebersihan area hotel, dan memberikan susasan yang } \\
\text { nyaman }\end{array}$ \\
\hline Mencermati waktu & Menciptakan tren baru di industri perhotelan \\
\hline
\end{tabular}

Sumber: Data diolah (2020)

\section{Prinsip 2: Menganalisis Kanvas Strategi dengan Baik}

Prinsip kedua ini menuntut manajemen suatu perusahaan jangan hanya melihat pada angka saja, melainkan harus fokus pada gambaran besar. Gambaran besar disini maksudnya kanvas stratagi. Kanvas strategi yang telah dibuat sebelumnya menggambarkan suatu kurva nilai dari Grand Malabar Hotel. Dari kanvas strategi dapat dilihat bahwa hampir semua faktor kompetisi secara tidak langsung bersaing dengan ketat. Hal ini nanti akan menjadi pertimbangan manajer hotel untuk melihat faktor-faktor mana saja yang dapat menjadi peluang dan berhasil di masa depan. kanvas strategi masa depan dibuat setelah analisis menggunakan pendekatan IPA dan kerangka kerja empat langkah, serta skema ERRC-Grid. Langkah dalam visualisasi strategi terlihat pada Tabel 3 . 
Tabel 3. Langkah dalam memvisualisasikan strategi Grand Malabar Hotel

\begin{tabular}{|c|c|c|c|}
\hline $\begin{array}{l}\text { 1. Melihat kanvas } \\
\text { strategi masa kini }\end{array}$ & 2. Eksplorasi visual & $\begin{array}{l}\text { 3. Menggambar kanvas } \\
\text { strategi masa depan }\end{array}$ & 4. Komunikasi visual \\
\hline $\begin{array}{l}\text { Pada langkah pertama ini } \\
\text { membandingkan kanvas } \\
\text { strategi Grand Malabar } \\
\text { Hotel dengan pesaingnya } \\
\text { pada tahun 2020, } \\
\text { kemudian melihat } \\
\text { perubahan apa yang } \\
\text { perlu dilakukan (Gambar } \\
\text { 1) }\end{array}$ & $\begin{array}{l}\text { Langkah kedua ini adalah } \\
\text { menganalisis ke lapangan } \\
\text { mengenai enam jalan untuk } \\
\text { menciptakan blue ocean. } \\
\text { Selanjutnya melihat faktor } \\
\text { apa yang harus dihapuskan, } \\
\text { ditingkatkan, ataupun } \\
\text { diubah. }\end{array}$ & $\begin{array}{l}\text { Menggambar kanvas strategi } \\
\text { masa depan berdasarkan } \\
\text { hasil lapangan, analisis IPA, } \\
\text { analisis pesaing, serta } \\
\text { analisis kepentingan dari } \\
\text { konsumen untuk } \\
\text { merumuskan strategi } \\
\text { berdasarkan kerangka kerja } \\
\text { empat langkah. }\end{array}$ & $\begin{array}{l}\text { Mengomunikasikan hasil } \\
\text { strategi yang didapat } \\
\text { kepada seluruh pihak } \\
\text { yang terlibat pada Grand } \\
\text { Malabar Hotel untuk } \\
\text { langkah perbaikan ke } \\
\text { depannya, sehingga } \\
\text { Grand Malabar Hotel } \\
\text { dapat mewujudkan blue } \\
\text { ocean dengan baik. }\end{array}$ \\
\hline
\end{tabular}

Sumber: Data diolah (2020)

\section{Prinsip 3: Menjangkau Konsumen yang Potensial}

Menjangkau konsumen yang luas tidaklah mudah apalagi menjangkau non-konsumen dari suatu industri. Pada prinsip ketiga ini suatu perusahaan harus melakukannya untuk memaksimalkan skala atau ukuran dari blue ocean. Ada tiga tingkatan non-konsumen yang harus dijangkau oleh Grand Malabar Hotel.

Non-konsumen tingkat pertama adalah orang yang datang dan menginap di hotel dengan suatu kebutuhan, misalnya memang butuh menginap di hotel untuk merasakan suatu yang berbeda atau memang tidak punya tempat menginap. Non-konsumen tingkat kedua adalah orang yang tidak mau membeli jasa yang ditawarkan karena memiliki alasannya merasa tidak efektif ataupun di luar jangkauan mereka. Nonkonsumen tingkat ketiga adalah orang yang paling jauh dari hotel. Non-konsumen tingkat ketiga ini merupakan konsumen yang dianggap kurang potensial bagi perusahan karena sudah dimiliki oleh pasar-pasar lain.

Untuk itu, Grand Malabar Hotel perlu memberikan kebutuhan non-konsumen tingkat pertama seperti pemberian harga yang terjangkau, suasana yang nyaman, dan fasilitas yang memadai. Kemudian untuk nonkonsumen tingkat kedua, cara yang dapat dilakukan yaitu memanfaatkan media sosial atau membuat website hotel. Penelitian (Romdonny \& Rosmadi, 2018; Sosiawan \& Sandhika, 2016) menyebutkan bahwa media sosial sangat berpengaruh terhadap pemasaran produk suatu organisasi dan kemudahan akses terhadap website juga berpengaruh terhadap pengalaman konsumen. Selain itu, dengan media sosial juga dapat menghemat biaya promosi dan dapat menjangkau masyarakat luas. Bagi non-konsumen level ketiga sebenarnya Grand Malabar Hotel dapat menjangkau konsumen hotel bintang 1 dan 2 serta hotel bintang 4 dan 5 dengan memberikan pelayanan yang baik dan penggunaan teknologi modern. Hal ini didukung oleh Nasar (2019) yang menyebutkan bahwa faktor pelayanan menjadi faktor paling besar bagi konsumen dalam menentukan keputusan menyewa hotel berbintang. Saat ini yang jadi non-konsumen pada masa depan bisa saja jadi konsumen Grand Malabar Hotel.

\section{Importance-Performance Analysis (IPA)}

Pendekatan IPA ini bertujuan untuk mengetahui kepuasan konsumen dengan membandingkan tingkat kinerja dan tingkat kepentingan. Langkah pertama yaitu mencari nilai rata-rata tingkat kinerja dan kepentingan setiap faktor kompetisi. Setelah itu mencari tingkat kesesuaian dengan membandingkan skor kinerja dan kepentingan. Kemudian langkah terakhir menghitung skor untuk analisis kaudran yang akan digunakan untuk membuat importance-performance matrix. 


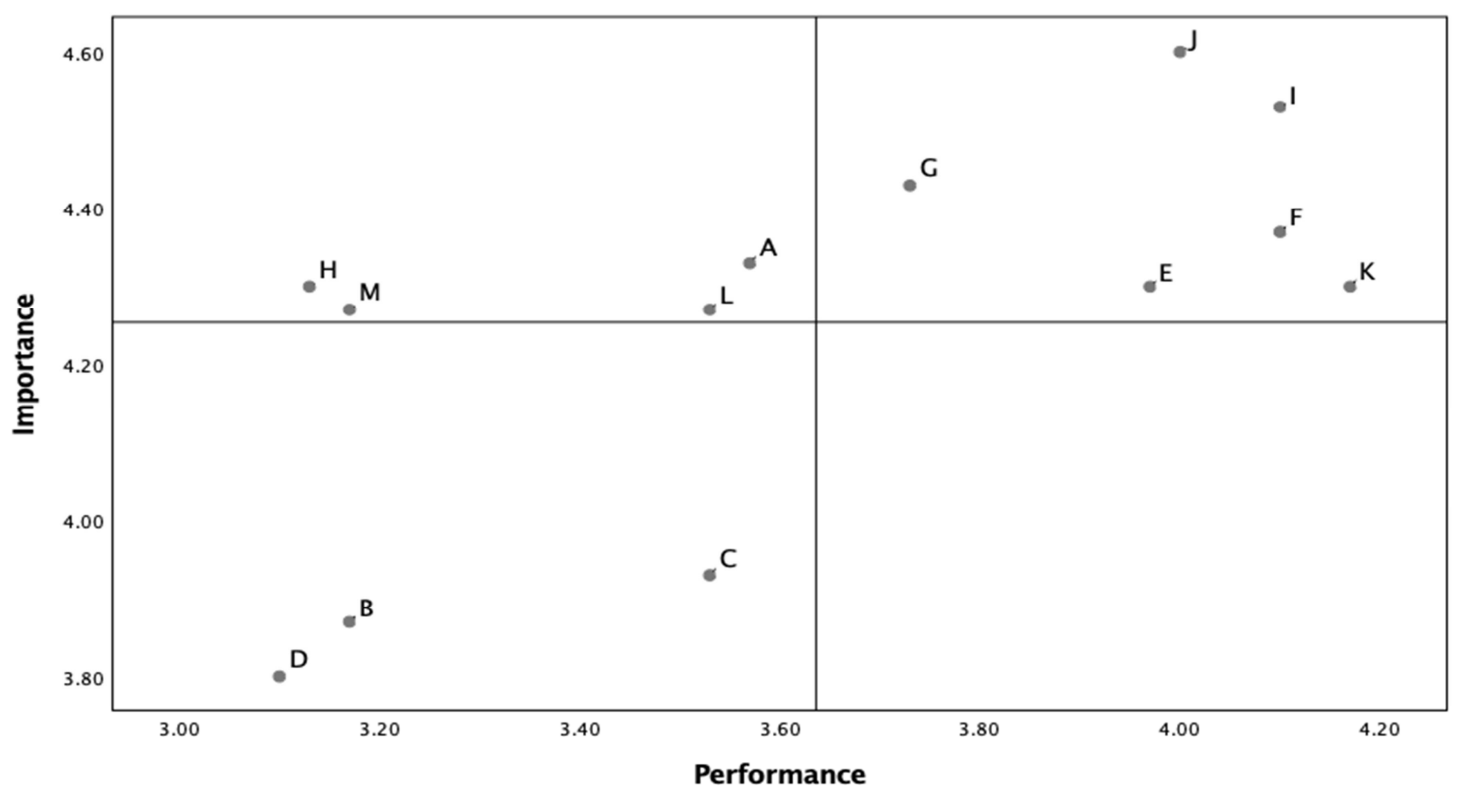

Sumber: Data diolah (2020)

Gambar 2. Importance-performance matrix Grand Malabar Hotel tahun 2020

Gambar 3 menunjukkan bahwa terdapat 4 kuadran dalam importance-performance matrix ini. Tetapi, dari 13 faktor yang dianalisis hanya masuk ke dalam 3 kuadran. Berikut penjelasan masing-masing kuadran.

Kuadran 1: Prioritas Utama

Faktor-faktor yang masuk pada kuadran 1 merupakan faktor-faktor yang dianggap penting tetapi kinerjanya masih kurang. Faktor yang masuk dalam kuadran ini antara lain, yaitu: faktor kamar yang bersih (A), aktif di media online (H), menawarkan fast check-out (L), dan desain bangunan hotel (M).

\section{Kuadran 2: Pertahankan}

Faktor-faktor yang berada di kuadran 2 meliputi faktor harga yang ditawarkan (E), lokasi yang strategis (F), parkir yang memadai (G), karyawan yang ramah (I), karyawan yang cepat tanggap (J), dan menawarkan online reservation (K). Faktor-faktor pada kuadran 2 harus dipertahankan karena sudah memiliki nilai kinerja dan kepentingan yang tinggi. Faktor ini umumnya sudah memiliki tingkat kepuasan konsumen yang tinggi.

\section{Kuadran 3: Prioritas Rendah}

Kuadran 3 memiliki arti prioritas rendah karena memiliki skor kinerja dan kepentingan yang rendah. Faktor yang masuk dalam kuadran 3, yaitu: faktor fasilitas kamar (B), fasilitas hotel (C), dan sarapan (D). Karena Grand Malabar merupakan hotel budget, sehingga mungkin orang-orang tidak berekspektasi terlalu tinggi pada faktor yang ada di kuadran 3 ini.

Faktor-faktor pada setiap kuadran ini akan digunakan sebagai pertimbangan dalam menyusun strategi menggunakan kerangka kerja empat langkah.

\section{Kuadran 4: Berlebihan}

Penelitian pada Grand Malabar Hotel tidak menunjukkan adanya satupun waktu yang masuk ke dalam kuadran 4. Artinya tidak ada faktor-faktor yang dianggap berlebihan.

\section{Kerangka Kerja Empat Langkah}

Membuat kurva nilai baru membutuhkan suatu kerangka kerja yang bertujuan untuk menciptakan inovasi nilai. Penjelasan kerangka kerja empat langkah sebagai berikut. 


\section{Hapuskan (Eliminate)}

a) Sarapan

Faktor sarapan saat ini tidak begitu penting bagi konsumen sesuai hasil analisis yang dilakukan. Hal ini karena kondisi pandemi yang sedang melanda hampir seluruh negara, sehingga rekomendasi yang ditawarkan ke manajemen Grand Malabar Hotel adalah meniadakan sarapan yang dilakukan secara prasmanan. Kemudian untuk sarapan dapat digantikan "by request" untuk menghindari kerumunan dan tetap menjaga jarak.

b) Fasilitas kamar

Berdasarkan hasil wawancara dengan manajer hotel, ada satu fasilitas yang ditawarkan oleh hotel yaitu safe deposit box (SDB). Faktor ini jarang digunakan karena segmen dari Grand Malabar Hotel ini juga menyasar terhadap wisatawan, bukan terhadap pebisnis, sehingga peneliti menyarankan SDB untuk ditiadakan.

c) Fasilitas hotel

Berdasarkan kavas strategi masa kini, terlihat bahwa faktor ini cukup bersaing secara ketat, untuk itu peneliti menyarankan Grand Malabar Hotel untuk mempertimbangkan fasilitas seperti car rental, bicycle rental, dan luggage storage untuk ditiadakan. Alasannya karena kondisi pandemi sekarang juga tidak mendukung untuk jasa ini, sehingga tidak perlu memberikan fokus ke faktor-faktor ini.

\section{Kurangkan (Reduce)}

a) Harga yang ditawarkan

Faktor ini bersaing secara sengit berdasarkan kanvas strategi masa kini. Rekomendasi yang ditawarkan bagi Grand Malabar Hotel adalah memberikan konsumen promosi atau potongan harga sekian persen untuk sebagian pengujung dan memberikan pengalaman unik saat menginap, sehingga diharapkan pada masa depan konsumen akan lebih puas terhadap Grand Malabar Hotel.

\section{Tingkatkan (Raise)}

a) Kebersihan kamar

Era pandemi Covid-19 kebersihan merupakan hal yang sangat penting diterapkan oleh industri perhotelan, khususnya kebersihan kamar yang merupakan tempat untuk mereka tidur. Hasil IPA menunjukkan bahwa kebersihan kamar masuk ke kuadran 1 (prioritas utama). Grand Malabar Hotel harus memfokuskan kebersihan di seluruh tempat, terutama di area kamar. Kebersihan dapat dilakukan dengan penyemprotan desinfektan dan harus dikontrol setiap harinya, sehingga konsumen percaya dan merasa aman saat menginap.

b) Aktif di media online

Menurut Umami (2015) promosi menjadi lebih mudah menggunakan media sosial. Karena hampir semua orang memiliki gadget yang bisa mengakses informasi dari mana saja dan kapan saja. Berdasarkan pendapat tersebut, Grand Malabar Hotel harus membuat media sosial seperti facebook, twitter, instagram untuk memberikan informasi tentang kamar, aktivitas, desain kamar, kontak hotel dan lain sebagainya. Sikap terhadap informasi dan niat membeli memiliki hubungan positif, semakin tinggi sikap terhadap informasi maka semakin tinggi niat membeli (Tjongirin et al., 2020). Hal ini didukung juga oleh (Rudyanto, 2018; Wiridjati \& Roesman, 2018) yang mengatakan bahwa jejaring sosial dan electronic word of mouth (E-WOM) memiliki pengaruh yang kuat terhadap niat beli konsumen terutama di generasi milenial.

c) Karyawan yang ramah

Pelayanan dari karyawan merupakan salah satu nilai penting dalam industri jasa. Karyawan yang ramah sangat diapresiasi oleh tamu yang menginap. Rekomendasi bagi pihak Grand Malabar Hotel yaitu lebih meningkatkan skill hospitality bagi setiap karyawan dengan pelatihan secara internal, agar konsumen puas dan ingin kembali menginap di Grand Malabar Hotel.

d) Karyawan yang cepat tanggap 
Berdasarkan hasil kanvas strategi masa kini, faktor ini sudah lebih baik dari pesaing utamanya, tetapi tetap harus ditingkatkan untuk menjadi lebih baik. Penelitian Baetie (2018) menyatakan bahwa kualitas pelayanan khususnya daya tanggap memiliki dampak positif terhadap kepuasan konsumen yang menginap. Untuk itu, pihak manajemen hotel dapat memberikan pelatihan dan edukasi tentang pelayanan khususnya daya tanggap.

e) Menawarkan online reservation

Grand Malabar Hotel saat ini sudah mendaftarkan di berbagai online travel agent (OTA). Menurut peneliti akan lebih baik juga hotel juga memiliki website hotel untuk memberikan informasi ketersediaan kamar, promosi, kolom saran, dan sebagainya untuk memberikan tamu berbagai alternatif untuk memesan kamar hotel.

f) Menawarkan fast check-out

Paisal (2013) mengatakan bahwa kepuasan konsumen yang tinggi berasal dari kecepatan check-in dan check-out. Rekomendasi bagi Grand Malabar Hotel adalah menawarkan fast check-out dengan cara memberikan formulir check-out saat mereka masih di kamar. Ini khusus untuk pemegang kartu kredit. Bagi yang tidak memiliki kartu kredit, proses pengecekan barang dan kamar mungkin bisa lebih dipercepat, sehingga tamu tidak menunggu lama.

g) Desain bangunan

Mengubah desain bangunan tidak selalu harus renovasi besar-besaran, karena akan buang waktu dan biaya yang besar. Desain hotel dapat dilakukan dengan mendesain ulang tata letak, memberikan hiasan di tempat tertentu, dan memberikan sentuhan minimalis baik di kamar, lobby, maupun ruang meeting. Aspek estetika dalam hal ini desain interior cukup memengaruhi preferensi konsumen dalam memilih hotel budget.

\section{Ciptakan (Create)}

a) Informasi tempat wisata

Tempat wisata yang banyak di Kota Bandung menjadi daya tarik tersendiri bagi wisatawan yang ingin berkunjung. Pihak Grand Malabar Hotel harus memanfaatkan hal ini dengan baik, seperti memberikan informasi tempat wisata pada hotel. Informasi ini dapat berupa layar yang ada pada lobby hotel. Hal ini bertujuan untuk memudahkan dan memberikan informasi tambahan pada tamu yang ingin berwisata.

b) Menjalin kerjasama dengan travel agent

Kerja sama yang bersifat mutualisme harus diciptakan. Sebagai contoh, Grand Malabar Hotel dapat memberikan special benefit kepada tamu yang menginap seperti potongan harga, merchandise, dan lain-lain. Bagi pihak travel hal ini menjadi alat promosi bagi orang-orang yang ingin menginap pada hotel yang memberikan special benefit.

c) Kiosk for self-check-in

Cheong et al. (2017) menyebutkan bahwa kios check-in ini memberikan kesempatan bagi tamu untuk check-in sendiri menggunakan barcode yang dikirim ke smartphone mereka, sehingga akan mengurangi waktu check-in pada sebuah hotel. Penelitian Kim \& Qu (2014) menjelaskan terdapat faktor eksternal seperti persepsi kegunaan, kemudahan, dan kompatibilitas memiliki pengaruh yang signifikan terhadap penggunaan kiosk for self-check-in. Jika Grand Malabar Hotel dapat mengadopsi teknologi ini, akan sangat baik dan menarik bagi konsumen.

d) Rooftop cafe

Larini \& Suryawan (2018) menyebutkan bahwa dengan adanya rooftop cafe akan menawarkan tamu untuk menikmati udara segar dan view dari ketinggian. Grand Malabar Hotel yang berada di tengah Kota Bandung dapat memanfaatkan hal ini dengan membuat cafe di lantai paling atas untuk memberikan pengalaman yang berbeda bagi tamu hotel.

e) Website hotel 
Website hotel memberikan banyak manfaat bagi masyarakat yang ingin melihat informasi tentang suatu hotel. Yulianto (2015) mengatakan bahwa website dan media sosial memiliki pengaruh positif terhadap tingkat hunian kamar hotel. Tentu, rekomendasi bagi Grand Malabar Hotel adalah membuat website untuk menjangkau konsumen yang lebih luas dan memberikan informasi seputar hotel.

f) Pemanfaatan internet of thing (IoT)

Verma \& Shukla (2019), IoT merupakan perubahan yang besar dan akan diimplementasikan di semua industri yang ada. IoT memberikan banyak manfaat bagi tamu, pengunjung, dan turis dalam hal fleksibilitas dan mobilitas. Grand Malabar Hotel dapat memanfaatkan IoT dalam hal TV, AC, pengendalian lampu, pemanfaatan robotic, dan peralatan lain yang dapat dikontrol dari smartphone. Hal ini dilakukan secara bertahap untuk menciptakan penawaran baru bagi konsumen di Indonesia.

\section{Skema ERRC-Grid}

Hasil analisis kerangka kerja empat langkah akan dimasukkan ke dalam skema ERRC-Grid. Skema ini berfungsi mendorong perusahaan untuk bertindak menciptakan kurva nilai baru (Kim \& Mauborgne, 2005). Skema ERRC-Grid ditunjukkan seperti Gambar 3.

\begin{tabular}{|l|l|}
\hline Eliminate (Hapuskan) & Raise (Tingkatkan) \\
- Sarapan & - Kebersihan kamar \\
- Fasilitas kamar & - Aktif di media online \\
& - Menawarkan fast check-out \\
& - Desain hotel \\
\hline Reduce (Kurangkan) & - Karyawan yang ramah \\
- Harga yang ditawarkan & - Menawarkan online reservation \\
\hline & Create (Ciptakan) \\
& - Kioskfor self check-in \\
& - Informasi tempat wisata \\
& - Rooftop cafe \\
\hline & - Menjalin kerjasama dengan travel \\
\hline
\end{tabular}

Sumber: Data diolah (2020)

\section{Gambar 3. Skema ERRC-Grid Grand Malabar Hotel tahun 2020}

Gambar 3 menunjukkan bahwa terdapat 3 faktor yang harus dihapuskan, 1 faktor yang harus dikurangkan, 7 faktor yang harus ditingkatkan, dan 6 faktor yang harus diciptakan. Hal ini direkomendasikan agar Grand Malabar Hotel bisa keluar dari red ocean.

\section{Kanvas Strategi Masa Depan}

Kanvas strategi masa depan ini merupakan hasil analisis dari metode IPA dan kerangka kerja empat langkah, serta skema ERRC-Grid. Pembuatan kanvas ini bertujuan untuk melihat faktor-faktor yang berubah dan yang dibutuhkan di masa depan. 


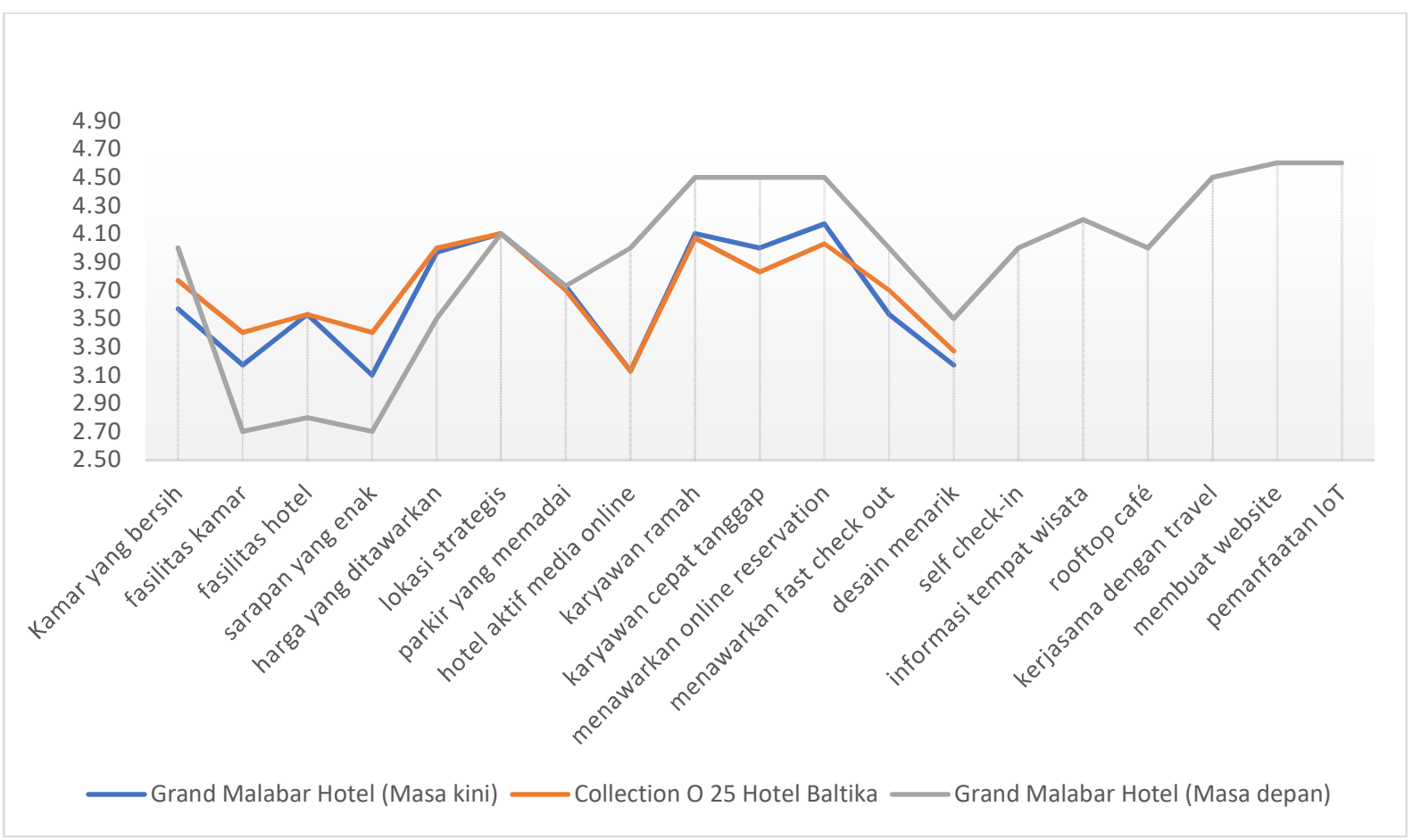

Sumber: Data diolah (2020)

\section{Gambar 4. Kanvas strategi Grand Malabar Hotel pada masa depan}

\section{Prinsip 4: Pengujian Blue Ocean Srategy (BOS)}

Kurva nilai baru berdasarkan Kim \& Mauborgne (2005) harus memiliki tiga ciri strategi yang efektif, yaitu: fokus, divergensi/gerak menjauh, dan moto yang memikat.

a) Fokus

Strategi yang direkomendasikan bagi Grand Malabar Hotel memiliki fokus untuk menciptakan pasar baru, memberikan manfaat bagi konsumen, dan meningkatkan penjualan hotel. Hal ini akan tercapai melalui enam faktor yang diciptakan pada masa depan, seperti informasi tempat wisata, kiosk for selfcheck-in, rooftop cafe, pemanfaatan IoT, membuat website, dan kerja sama dengan travel agent.

b) Gerak menjauh

Gambar 5 memperlihatkan bahwa kurva nilai baru sudah memiliki ciri kedua yaitu gerak menjauh. Hampir semua faktor pada kurva nilai baru menjauh dari pesaingnya. Hal ini didapat setelah dianalisis dan dirumuskan menggunakan hasil IPA dan kerangka kerja empat langkah. Kim \& Mauborgne (2005) menjelaskan jika kurva nilai baru sudah bergerak menjauh dari pesaingnya berarti perusahaan sudah berhasil melihat alternatif yang dapat menjadi peluang.

c) Moto yang memikat

Moto yang memikat merupakan suatu strategi bagi perusahaan untuk mendapatkan kepercayaan dan kekuatan dari masyarakat. Moto yang harus digunakan oleh Grand Malabar Hotel adalah "Stay comfort and modern with Grand Malabar Hotel". Moto ini memiliki makna bahwa Grand Malabar Hotel menawarkan pelayanan yang baik dan kesan modern agar konsumen puas terhadap Grand Malabar Hotel.

Langkah selanjutnya adalah tahap pengujian strategi sebelum masuk ke tahap eksekusi. Pada prinsip ini ada empat pernyataan yang harus dilewati untuk mencapai blue ocean strategy. Pertama adalah utilitas bagi pembeli, kedua harga, ketiga biaya, dan keempat hambatan pengadopsian.

Utilitas bagi Pembeli

1) Kecepatan saat check-in

2) Memberikan informasi terkait wisata di Kota Bandung

3) Penawaran spesial 
Sumber: Data diolah (2020)

Gambar 5. Pengujian blue ocean strategy menggunakan rangkaian strategis yang benar

\section{Implikasi Manajerial}

Implikasi manajerial diwujudkan sebagai alternatif strategi bersaing pada Grand Malabar Hotel yang dirumuskan dengan keadaan saat ini. Menurut Hanifah et al. (2015), blue ocean strategy adalah untuk menciptakan pangsa pasar baru yang belum diciptakan pesaing lewat inovasi yang dilakukan secara berkelanjutan. Tahapan yang harus dilakukan pertama adalah hapuskan, kurangkan, dan tingkatkan. Karena dalam mengimplementasikan ide ini tidak terlalu memakan biaya dan waktu yang besar.

Tahapan selanjutnya adalah menciptakan enam faktor baru yang menurut hasil analisis berpeluang menciptakan blue ocean. Faktor-faktor ini akan disusun berdasarkan tingkat kepentingan tertinggi hingga terendah. Nilai tingkat kepentingan ini didapat dari pengambilan data pada kuesioner tahap kedua. Faktor yang diciptakan pertama adalah kerjasama dengan travel agent, faktor kedua adalah website hotel, faktor ketiga adalah informasi tempat wisata, faktor keempat pemanfaatan IoT, faktor kelima kiosk for self-checkin, dan faktor terakhir adalah rooftop cafe.

Tabel 4. Program kerja Grand Malabar Hotel

\begin{tabular}{ccccc}
\hline No & Ide blue ocean & Program & Prioritas & Jangka \\
\hline & 227 & &
\end{tabular}




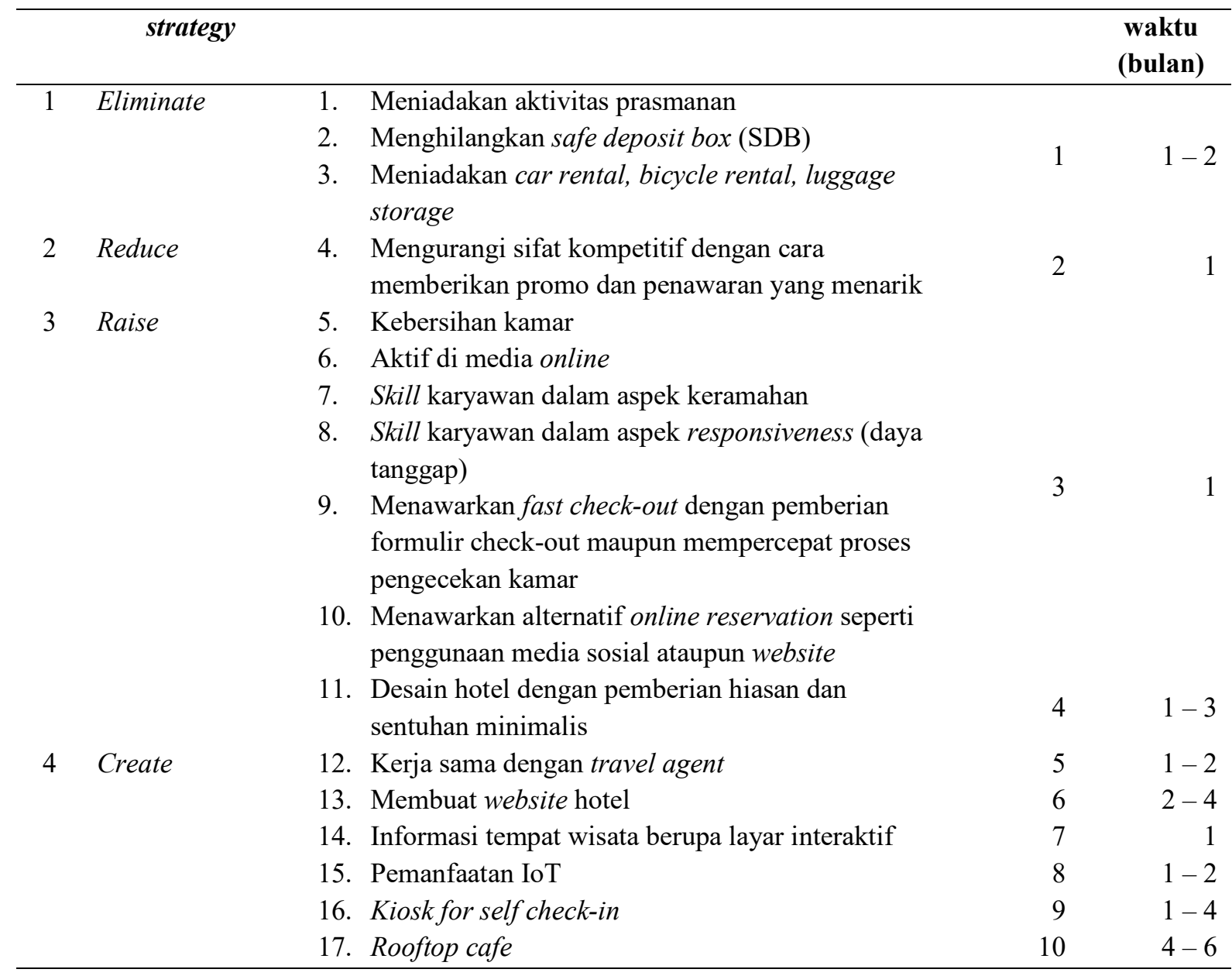

Dalam upaya menerapkan blue ocean strategy, pihak manajemen Grand Malabar Hotel harus menyiapkan sumber daya, baik sumber daya manusia maupun sumber daya modal, sehingga waktu dieksekusi akan memberikan dampak positif bagi hotel. Prayudha \& Harsanto (2020) menjelaskan di dalam perhotelan, praktik sumber daya manusia secara langsung memengaruhi persepsi tamu terhadap kualitas pelayanan, sehingga apabila Grand Malabar Hotel mempersiapkannya dengan baik maka akan berdampak positif bagi hotel.

\section{KESIMPULAN}

Berdasarkan hasil analisis dapat disimpulkan bahwa terdapat 13 faktor yang menjadi ajang kompetisi pada industri hotel di Kota Bandung. Faktor-faktor tersebut antara lain: kebersihan kamar, fasilitas kamar, fasilitas hotel, sarapan, harga yang ditawarkan, lokasi, parkir, karyawan yang ramah, karyawan yang cepat tanggap, aktif di media online, menawarkan online reservation, menawarkan fast check-out, dan desain hotel. Kanvas strategi tahun 2020 menggambarkan bahwa persaingan industri hotel masuk ke dalam samudera merah. persaingan antara Grand Malabar Hotel dengan Collection O 25 Hotel Baltika terlihat pada kurva nilai yang sebagian besar berhimpitan. Hampir semua faktor dari kedua hotel ini bersaing secara ketat.

Perumusan ide blue ocean strategy didapatkan melalui: (1) eliminasi faktor sarapan dalam bentuk prasmanan, fasilitas hotel yang berupa SDB, fasilitas hotel yang berupa car rental, bicycle rental, dan luggage storage; (2) mengurangi faktor harga yang ditawarkan; (3) meningkatkan faktor kebersihan kamar, aktif di media online, menawarkan online reservation, memperindah desain hotel, skill karyawan dalam bentuk keramahan, skill karyawan dalam bentuk kecepatan daya tanggap, dan menawarkan fast check-out; (4) menciptakan faktor kerja sama dengan agen perjalanan, membuat website hotel, kiosk for self-check-in, 
informasi tempat wisata, dan pemanfaatan internet of thing (IoT). Terakhir setelah melewati pengujian menggunakan tiga ciri strategi yang efektif dan rangkaian strategis yang tepat didapatkan ide blue ocean yang layak secara komersil bagi Grand Malabar Hotel.

\section{SARAN TEORITIS}

Peneliti menyadari bahwa ada beberapa keterbatasan dalam penelitian ini. Pertama, penelitian ini hanya berfokus kepada empat prinsip awal blue ocean strategy. Prinsip-prinsip tersebut adalah mencari peluang-peluang strategis, menganalisis kanvas strategi dengan baik, dan menjangkau konsumen yang potensial, dan melakukan pengujian terhadap blue ocean strategy. Empat prinsip ini bertujuan untuk menyusun perencanaan bagi suatu bisnis agar dapat bersaing. Hasilnya penelitian ini hanya dapat merencanakan dan tidak sampai kepada prinsip eksekusi. Kedua penelitian ini hanya berfokus kepada satu hotel di Kota Bandung yang mungkin tidak dapat digeneralisasi. Bagi peneliti selanjutnya, diharapkan dapat melanjutkan penelitian ini untuk mengetahui hambatan-hambatan yang terjadi saat strategi ini sudah dieksekusi dan dalam jangka waktu yang lebih lama.

\section{SARAN PRAKTIS}

Kemudian saran yang dapat diberikan berdasarkan hasil penelitian ini adalah bagi pihak Grand Malabar Hotel, pihak manajemen hotel dapat mempertimbangkan ide blue ocean ini untuk menjadi alternatif strategi dalam persaingan yang ketat ini. Lalu pihak manajemen hotel harus berinovasi secara berkelanjutan agar tetap dapat menawarkan hal-hal baru dan menjadi pioneer dalam industri hotel di Indonesia.

\section{REFERENSI}

Adicandra, A. (2017). Strategi pengembangan bisnis berdasarkan blue ocean strategy pada PT. Inti Lautan Fajar Abadi. Agora, 5(1), 1-7.

Arifin, S. M., \& Abdillah, Y. (2018). Penerapan blue ocean strategy (BOS) dalam usaha memasuki pasar internasional (Studi pada UMKM Pricilla Jilbab Bolak Balik ). Jurnal Administrasi Bisnis (JAB), 61(2), $38-47$.

Badan Pusat Statistik. (2020). Statistik Dasar Sektor Pariwisata. Statistik Indonesia 2020. https://www.bps.go.id.

Baetie, D. (2018). Pengaruh kualitas pelayanan terhadap kepuasan tamu di Hotel Niagara Parapat Provinsi Sumatera Utara. Jom Fisip, 5(1), 1-27.

Caesari, S., Nugraha, H. S., \& Prabawani, B. (2015). Analisis faktor-faktor yang mempengaruhi konsumen untuk menginap di Hotel Puri Saron. Diponegoro Journal of Social and Political of Science, 4, 1-11.

Cheong, S. N., Ling, H. C., Teh, P. L., Ahmed, P. K., \& Yap, W. J. (2017). Encrypted quick response scheme for hotel check-in and access control system. International Journal of Engineering Business Management, 9, 1-9. https://doi.org/10.1177/1847979017720039

David, R. F. (2011). Managemen Strategik (13th ed.). Pearson Education. New Jersey.

Hanifah, H., Setyawati, A., \& Octaviani, R. D. (2015). The implementation of blue ocean strategy to create a market niche. Jurnal Manajemen Transportasi dan Logistik, 2(2), 191-198. https://doi.org/10.25292/j.mtl.v2i2.118

Kim, M., \& Qu, H. (2014). "Traveler's behavioral intention toward hotel self-service kiosks usage." International Journal of Contemporary Hospitality Management, 26(2), 225-245.

Kim, W. C., \& Mauborgne, R. (2005). Blue Ocean Strategy. Harvard Business Review Press. Boston.

Kosasih, K. M. C., \& Indriyani, R. (2014). Perumusan blue ocean strategy sebagai strategi bersaing pada perusahaan keluarga CV. Gama Abadi. Agora, 2(1), 1-9.

Kusnita, K. L. (2019). Blue ocean strategy di industri perhotelan. Jurnal Manajemen Bisnis, 16(3), 122-134. http://journal.undiknas.ac.id/index.php/magister-manajemen/article/view/2236

Larini, C., \& Suryawan, I. B. (2018). Trend rooftop restaurant and bar sebagai daya tarik wisata kuliner di DKI Jakarta. Jurnal Destinasi Pariwisata, 6(2), 371-378. https://doi.org/10.24843/jdepar.2018.v06.i02.p27

Leavy, B. (2018). Value innovation and how to successfully incubate "blue ocean" initiatives. Strategy and Leadership, 46(3), 10-20. 
Nadhifa, B., \& Sharif, O. O. (2019). Analisis custumer value index dalam memilih atribut hotel bintang dua di Kota Jakarta. Jurnal Manajemen dan Bisnis, 3(1), 174-183.

Nasar, A. (2019). Perilaku konsumen dalam melakukan keputusan menyewa kamar hotel berbintang untuk meningkatkan pariwisata di wilayah Kotamadya Kupang. Tourism - Jurnal Pariwisata, 2(1), 64-71. https://doi.org/10.32511/tourism.v2i1.320

Paisal. (2013). Pengaruh kualitas layanan terhadap kepuasan konsumen. Jurnal Manajemen dan Bisnis Sriwijaya, 11(4).

Prayudha, A. N., \& Harsanto, B. (2020). Integration of service quality, benchmarking and Ishikawa diagram in service operations. Jurnal Manajemen dan Pemasaran Jasa, 13(2), 151-166. https://doi.org/10.25105/jmpj.v13i2.6144

Pristanto, Y., Wahyuni, S., \& Handini, Y. D. (2012). Analisis faktor-faktor yang mempengaruhi keputusan menginap pada Hotel Bintang Mulia Jember. Artikel Ilmiah, 1(1), 1-6.

Romdonny, J., \& Rosmadi, M. L. N. (2018). Peran media sosial dalam mendukung pemasaran produk organisasi bisnis. Ikra-Ith Ekonomika, 1(2), 25-30.

Rudyanto. (2018). Pengaruh pemasaran jejaring media sosial dan keterkaitan konsumen terhadap niat beli konsumen. Jurnal Manajemen dan Pemasaran Jasa, 11(2), 177-200. https://doi.org/10.25105/jmpj.v11i2.3126

Schwab, K. (2016). The Fourth Industrial Revolution. World Economic Forum. Switzerland.

Shyam, R., \& Geevarathna. (2019). Exploring uncontested markets with blue ocean strategy in convenience food business-a case of Id Fresh Food. Journal of the International Academy for Case Studies, 25(1), $1-7$.

Sosiawan, M., \& Sandhika, V. V. (2016). Analisa dimensi website yang mempengaruhi keputusan konsumen Surabaya dalam melakukan reservasi hotel secara online. Hospitality dan Manajemen Jasa, 4, 70-88. http://publication.petra.ac.id/index.php/manajemen-perhotelan/article/view/4131/3784

Sugihamretha, I. D. G. (2020). Respon kebijakan: Mitigasi dampak wabah Covid-19 pada sektor pariwisata. The Indonesian Journal of Development Planning, 4(2), 191-206. https://doi.org/10.36574/jpp.v4i2.113

Susilawati, S., Falefi, R., \& Purwoko, A. (2020). Impact of COVID-19's pandemic on the economy of Indonesia. Budapest International Research and Critics Institute (BIRCI-Journal): Humanities and Social Sciences, 3(2), 1147-1156. https://doi.org/10.33258/birci.v3i2.954

Suwarni, Rachmat, H., Nugaraha, A., \& Edyanat, C. (2020). Kepariwisataan terkait 4.0 dengan memanfaatkan big data. Tornare, 2(1), 22-25. https://doi.org/10.24198/tornare.v2i1.25829

Thursena, M. (2016). Perumusan blue ocean strategy untuk strategi bersaing pada pusat perbelanjaan DP Mall Semarang. (Tesis). Retrieved from http://repository.unika.ac.id/13406/.

Tjongirin, R., Gianto, M., \& Sihombing, S. (2020). Applying the information acceptance model to predict purchase intention in social media. Jurnal Manajemen Dan Pemasaran Jasa, 13(2), 263-280. https://doi.org/10.25105/jmpj.v13i2.6234

Traveloka. (2020). Rating hotel di Kota Bandung. Www.Traveloka.Com.

Uchenna, T., \& Ekwy, M. (2019). Assessment of business enterprise and strategic thinking: A study of steady growth Nigeria limited. Indian Journal of Commerce \& Management Studies, 10(2), 31-36. https://doi.org/10.18843/ijcms/v10i2/05

Umami, Z. (2015). Social strategy pada media sosial untuk promosi pariwisata Daerah Istimewa Yogyakarta. INTERAKSI: Jurnal Ilmu Komunikasi, 4(2), 195-201. https://doi.org/10.14710/interaksi,4,2,195-201

Verma, A., \& Shukla, V. (2019). Analyzing the influence of IoT in tourism industry. SSRN Electronic Journal, January, 2083-2093. https://doi.org/10.2139/ssrn.3358168

Widyastutik, Panjaitan, I., Malau, F., \& Fahreiza, Y. (2020). Strategi peningkatan daya saing sektor jasa pariwisata Indonesia: Studi kasus jasa pariwisata Danau Toba dan Bali. Jurnal Aplikasi Manajemen dan Bisnis, 6(2), 356-368. https://doi.org/10.17358/jabm.6.2.356

Wiridjati, W., \& Roesman, R. R. (2018). Fenomena penggunaan media sosial dan pengaruh teman sebaya pada generasi milenial terhadap keputusan pembelian. Jurnal Manajemen dan Pemasaran Jasa, 11(2), 275-290. http://dx.doi.org/10.25105/jmpj.v11i2.2950

Yulianto, A. (2015). Kajian internet marketing sebagai salah satu media pemasaran industri perhotelan. Jurnal Khasanah Ilmu, 6(1), 65-78. https://doi.org/10.31294/khi.v6i1.526 